\title{
Os orçamentos participativos como instrumento de participação popular na efetivação das políticas públicas
}

\author{
Gabriela Soares Balestero ${ }^{1}$
}

\section{Resumo}

A valorização da democracia direta é objeto do debate político mundial. A repulsa da população pela política e pelas atuais formas de democracia representativa traz a reflexão sobre a necessidade da participação direta popular no que tange à destinação das verbas públicas com a finalidade de propiciar a efetivação de políticas públicas. Ao analisar os orçamentos participativos, ressalta-se a necessidade de valorizar a democracia direta participativa, de maneira a dotar de legitimidade as decisões oriundas do poder público bem como atender os problemas da comunidade.

Palavras-chave: Democracia direta. Repulsa. Orçamentos participativos. Participação popular. Democracia.

\section{Introdução}

No presente estudo, será analisada a possibilidade de melhoria na efetivação de políticas públicas mediante a participação direta dos cidadãos na elaboração da proposta orçamentária e a destinação dos recursos públicos.

A elaboração do orçamento municipal é uma atribuição do Poder Executivo, pois é o responsável pela apresentação de uma proposta orçamentária à Câmara Municipal de Vereadores, a qual decide sobre as alterações possíveis.

\footnotetext{
${ }^{1}$ Advogada militante graduada pela Universidade Presbiteriana Mackenzie em 2006. Mestranda em Direito Constitucional pela Faculdade de Direito do Sul de Minas, especialista em Direito Constitucional e em Direito Processual Civil pela Faculdade de Direito do Sul de Minas. Endereço eletrônico para contato: gabybalestero@yahoo.com.br.
} 
Destaca-se que a Constituição Brasileira de 1988 pretende possibilitar a superação das desigualdades sociais e regionais por meio do progressivo aprofundamento da democracia participativa, social, econômica e cultural, só possível com o fortalecimento da esfera pública política, de uma opinião pública livre e de uma sociedade civil organizada e atuante.

Portanto, para assegurar a eficácia e a efetividade dos direitos fundamentais, bem como a participação mais ativa da população, o agente público pode aferir prioridades acerca dos investimentos públicos diretamente com a população, apresentando posteriormente tais propostas orçamentárias à Câmara Municipal.

Nesse sentido, a população passaria a ser corresponsável pela elaboração dos orçamentos públicos bem como pela destinação das políticas públicas, no sentido de limitar o uso indiscriminado da coisa pública pela administração e proporcionar a melhoria do funcionamento da democracia participativa.

Portanto, o objetivo deste artigo é discutir a importante experiência do orçamento participativo como fortalecimento do poder local e instrumento de incentivo à participação direta dos cidadãos, utilizando-se a teoria procedimentalista de Jürgen Habermas, e apresentando pontos positivos e negativos que necessitam ser reformulados no modelo brasileiro.

\section{Os fatores de crise da democracia}

Em nosso país, há entraves para a consolidação das instituições democráticas, pois a experiência constitucional brasileira revela um sistema econômico excludente e perverso, no qual há ainda a predominância de uma classe dominante, elitista, que concentra riquezas e obstaculariza as reformas sociais.

Os fatores de crise compreendem: a) globalização; b) complexidade; c) risco; d) crise do princípio representativo; e d) fenomenologia do refluxo. 
A globalização ${ }^{2}$ é um fenômeno social, econômico, político, além de universal, pois desloca muitas decisões para fora do país, havendo, nesse sentido, uma interpenetração entre os níveis local e global, passando a política interna a ser influenciada por fatores externos, restringindo a autonomia e a liberdade popular.

A complexidade é a dificuldade de adaptação da democracia em uma sociedade complexa. Segundo Ulrich Beck ${ }^{3}$, a sociedade de risco "[...] designa um tipo de sociedade que se tornou consciente do paradoxo do conhecimento científico, ou seja, de que a produção de novos conhecimentos gera novas incertezas".

Há o confronto entre a democracia e a tecnocracia, havendo dúvidas quanto à competência e à capacidade do povo em suas decisões. Portanto, a democracia é desafiada a resolver temas que fogem à cognição da própria ciência.

A democracia encontra-se abalada e, ao mesmo tempo, desafiada diante de tais situações no que tange à sua capacidade para solucionar questões que fogem ao controle da própria ciência experimental e tecnológica. Como exemplo dessa situação, destaca-se a crise econômica atual, ocasionada pela tecnocracia que, sem forças suficientes para trazer soluções, busca a política que, mesmo abalada, possui o encargo de solucioná-la.

2 "Em síntese, a globalização gera a contestação da primazia do Estado como único agente de regulação política, como pólo ilhado definidor da prática governamental. A concorrência com agências e forças econômicas transnacionais e o impacto produzido por diretrizes de ação tomadas em razão do conglomerado de interesses econômicos do setor privado internacional e dos Estados hegemônicos são, pois, as causas diretas do descompasso entre os conceitos de soberania estatal e governabilidade. É necessário, portanto, insistir na tese da necessidade do Estado, ainda que em contextos de diluição do conceito clássico de soberania. Ao Estado cabe ainda encontrar um pouco relativamente estável a partir do qual se possam viabilizar, em termos pragmáticos, estratégias adaptativas que evitem transformá-lo de 'primário' em 'precário." PEREIRA, Rodolfo Viana. Direito constitucional democrático. Rio de Janeiro: Lúmen Júris, 2008. p. 121-122.

3 PEREIRA, Rodolfo Viana. Direito constitucional democrático. Rio de Janeiro: Lúmen Júris, 2008. p. 127. 
Além disso, verifica-se que desde a implantação do Estado de Direito, a democracia indireta monopolizou os sistemas democráticos, de forma a traduzir o que seria a efetiva realização da soberania popular.

Apesar da inclusão constitucional de institutos de democracia direta, como o referendo, o plebiscito e a iniciativa popular, verifica-se a predominância da representação ${ }^{4}$.

Contudo, o apelo à participação configura-se mais como uma consequência da crise do que a sua causa, pois uma das maiores causas da crise da representatividade é o descrédito do cidadão, a quebra da confiança, sobretudo quanto à idoneidade, à capacidade das instituições e dos agentes políticos. Entretanto, diante da incoerência entre a ideologia dos partidos e a sua prática, os cidadãos de hoje consideram muitos partidos como um mal necessário da democracia. Além disso, constata-se que a queda no desempenho prestacional das instituições representativas é uma das causas de insatisfação do regime democrático.

Dessa forma, tudo isso resulta em um aumento ainda maior da insatisfação dos governados em face de seus governantes, contribuindo no afastamento entre o cidadão e as instituições democráticas.

O último fator de crise é representado pelo "refluxo à democracia”, expressão essa que designa uma categoria de eventos que inclui três fenômenos particulares: o afastamento da política, a renúncia à política e a recusa à política.

O fenômeno repulsivo à democracia se deve principalmente em razão das promessas não cumpridas pela democracia: a má distribuição do poder, a representação dos interesses neocorporativos, a inviabilidade de uma sociedade iguali-

\footnotetext{
4 "A historiografia da democracia indireta registra alguns momentos de instabilidade e de necessidade de readaptação dos seus pressupostos. É o caso verificado, por exemplo, durante os processos de universalização do sufrágio e de surgimento dos partidos políticos de massa em fins do século XIX, que chegaram a ser interpretados por muitos como fatores de crise". PEREIRA, Rodolfo Viana. Direito constitucional democrático. Rio de Janeiro: Lúmen Júris, 2008. p. 124.
} 
tária diante do poder das elites corporativas, de forma a ocasionar o descaso pela política de grande parte da sociedade.

Portanto, conclui-se que a deficiência na eficiência da democracia ocasiona o afastamento crescente entre os cidadãos e as instâncias de decisão.

A doutrina atual se projeta no sentido de dar plena aplicabilidade às normas constitucionais, ressaltando que as decisões do Poder Público para a efetivação de suas metas de ação não são invioláveis, tendo em vista que, no âmbito do Estado Democrático de Direito, é possível a participação direta na destinação da verba pública, de maneira a haver maior controle social quanto à destinação dos gastos públicos.

\section{Os orçamentos participativos e a experiência brasileira}

A crise do sistema democrático leva a discussão sobre a necessidade de readaptação dos seus elementos à complexidade da sociedade moderna, com o fim de proporcionar maior participação dos governados.

A sugestão, portanto, é resgatar elementos da democracia direta, reconhecendo a atuação de atores coletivos na esfera pública, de maneira a resgatar a democracia direta, com a abertura do Estado à participação popular.

Mas para atingir esse objetivo, Habermas indica transformações necessárias ao modo de produção e aplicação do direito. A fundamentação do direito e do Estado Democrático vai ser deslocada, da soberania do povo, para a soberania de um procedimento discursivo público sob condições ideais. O resultado é uma reconfiguração da separação dos poderes de acordo com os tipos de discursos predominantes em cada um deles. $\mathrm{O}$ poder administrativo (executivo), o legislativo e o judiciário ganham assim atribuições e competências cuja legitimidade pressupõe outro poder, chamado por Habermas de 'poder comunicativo', que é o poder resultante de uma discussão 
pública racional onde todos os implicados passam a ser, ao mesmo tempo, destinatários e autores do próprio direito. ${ }^{5}$

No campo da participação discursiva e deliberativa dos interessados, Jürgen Habermas, por intermédio da Teoria do Discurso, trouxe uma contribuição ao campo jurídico e social, na qual o Direito é um meio de integração social, um mediador da tensão entre a facticidade, ou seja, o mundo real e a validade. ${ }^{6}$

Para Habermas, a teoria do Direito, sendo apoiada na Teoria do Discurso necessita sair da filosofia política e do direito e se expandir, ocasionando a reflexão sobre a possibilidade da construção de uma sociedade realmente pautada na justiça e na democracia.

Nesse passo, segundo ensinamento de Habermas, por intermédio do discurso, da ação comunicativa, buscam-se alternativas filosóficas que possam fundar a integração social e a racionalidade nos processos sociais de formação democrática da vontade do povo. O discurso promove a inclusão de toda e qualquer minoria. ${ }^{7}$

5 PEREIRA, Rodolfo Viana. Direito constitucional democrático. Rio de Janeiro: Lúmen Júris, 2008. p. 12.

6 "A tensão entre facticidade e validade, que se introduz no próprio modo de coordenação da ação, coloca exigências elevadas para a manutenção de ordens sociais. O mundo da vida, as instituições que surgem naturalmente e o direito têm que amortizar as instabilidades de um tipo de socialização que se realiza através de tomadas de posição - em termos de sim/ não com relação a pretensões de validade criticáveis". HABERMAS, Jürgen. Direito e democracia entre a facticidade e a validade. 2. ed. Rio de Janeiro: Tempo Brasileiro, 2003. p.25-26.

7 O ativismo judicial se insere no Brasil dentro de um mundo da vida em que os juízes, de uma forma geral, não se sentem servidores públicos, e sim, entes transcendentalmente superiores. Acostumados à cortesia e às posturas formalistas, não é incomum a figura do magistrado distante das pessoas e do "mundo" que espera apenas a bajulação e desconsidera as necessidades das partes. Dizer a eles que podem tudo, ou melhor, que devem fazer tudo, tal como fazem os teóricos do constitucionalismo da efetividade, é música para seus ouvidos! Não desconhecemos que as intenções dessa corrente teórica são boas e favoráveis à inclusão social. Mas é preciso lembrar o ditado: o inferno está cheio de boas intenções. $\mathrm{O}$ ativismo judicial desmedido por noções vazias como "razoabilidade" e "proporcionalidade" pode ser um bálsamo, como pretendem seus adeptos, mas também pode ser um veneno para nossa democracia ainda incipiente. Sem pretensão de estabelecer "verdades", no mínimo, acreditamos firmemente que a denúncia de Habermas serve de base para reflexão do modo de operação do direito e do constitucionalismo nacionais." CRUZ, Álvaro Ricardo de Souza. Habermas e o direito brasileiro. 2.ed. Rio de Janeiro: Lúmen Júris, 2008. p. 251. 
A herança deixada por Habermas é a recomendação de que em um Estado Democrático de Direito, todos os atingidos e possíveis atingidos pelas decisões devem participar delas de forma ativa.

Nesse sentido, Habermas apresenta uma proposta baseada na Teoria do Discurso, que é a integração entre o Estado e a Sociedade Civil por intermédio de uma política deliberativa. ${ }^{8}$

Nesse passo, a legitimidade ${ }^{9}$ seria uma condição da força normativa do direito, transferindo o problema da realização dos direitos, que possui cerne positivista, para se tornar um problema de legitimação. Para isso, Habermas propõe um novo paradigma para o direito, denominado "procedimentalismo", no qual o direito gerado através do discurso democrático pode transformar a realidade, de maneira a diminuir as tensões sociais que existem.

Jürgen Habermas atribui um papel central à linguagem no processo de formação de opinião e da vontade dos cidadãos. Tal teoria se desenvolve no interior de um Estado Democrático de Direito que se pressupõe a existência de um espaço público não restrito ao âmbito estatal, de uma comunidade de homens livres e iguais capazes de criar as leis que os regem e onde os próprios envolvidos têm de entrar em acordo, prevalecendo a força do melhor argumento.

Nesse contexto, é necessário criar instituições que canalizem o direito à participação direta na gestão política, de maneira a qualificar as políticas públicas, dando-lhes maior eficiência, pois alcançarão efetivamente as necessidades da comunidade.

${ }^{8}$ CRUZ, Álvaro Ricardo de Souza. Habermas e o direito brasileiro. 2.ed. Rio de Janeiro: Lúmen Júris, 2008. p. 32.

9 "Essa legitimidade democrática, na modernidade, cabe esclarecer, remete-se ao chamado vínculo ou coesão interna entre Estado de Direito e Democracia, de que nos fala Habermas, fundamentalmente a partir do Direito e Democracia: entre fadicidade e validade." OLIVEIRA, Marcelo Andrade Cattoni de. Direito, politica e filosofia: contribuições para uma teoria discursiva da constituição democrática no marco do patriotismo constitucional. Rio de Janeiro: Lúmen Júris, 2007. p. 5. 
Uma experiência muito interessante de efetivação prática do procedimentalismo democrático habermasiano são os orçamentos participativos ${ }^{10}$ que tiveram início com o primeiro orçamento participativo municipal na cidade de Pelotas ${ }^{11}$ no Rio Grande do Sul, sendo depois encaminhado para Porto Alegre.

Segundo José Luiz Quadros de Magalhães"12, “o orçamento participativo é um importante mecanismo de democracia participativa que permite a integração do cidadão e de grupos de cidadãos na construção da democracia local do Brasil”.

Diante dos fatores de desestabilização democrática analisados anteriormente, o fortalecimento da democracia implica na ampliação de instrumentos de

10 "É importante lembrar que a organização da sociedade civil que permite o avanço do poder local democrático participativo encontra suas bases nos movimentos de resistência à ditadura civil - militar de direita (1962-1985), no movimento de formação das comunidades eclesiais de base e no movimento sindical no final da década de 1970, movimentos que estão na base da criação do Partido dos Trabalhadores." MAGALHÃES, José Luiz Quadros de. Direito constitucional. Belo Horizonte: Mandamentos, 2006. v. 3. p. 39-40.

${ }^{11}$ Desde os anos oitenta, o Partido dos Trabalhadores (PT) tem utilizado o Orçamento Participativo como ferramenta de gestão, sobretudo municipal. Mas embora a prática seja amplamente interiorizada no âmbito do PT como ferramenta de governo hábil a caracterizar o bom gestor, é importante ressaltar que as primeiras iniciativas de participação direta do povo na definição das políticas públicas de governo não partiram do PT. Já na década de 70, o PMDB, em algumas de suas administrações, estimulava a participação popular. Consequência disso é que, no início da década seguinte, grandes metrópoles passaram a adotar estratégias embrionárias de participação ativa da sociedade que sucederam nos modelos de Orçamento Participativo que hoje são frequentemente vistos em governos petistas. É o caso, por exemplo, do Orçamento Participativo em Porto Alegre, formalmente instituído no governo municipal petista de Olívio Dutra (1989-1992), mas cuja ideia embrionária remonta aos Conselhos Populares da gestão de Alceu Collares (1985-1988), do PDT. Sendo relevante salientar que, no início da década de oitenta, o Partido dos Trabalhadores ainda era um partido incipiente, pois foi fundado em 10 de fevereiro de 1980, e muitos dos agentes criaram a discussão sobre a participação popular direta naquele período pertenciam a outras agremiações partidárias e posteriormente migraram para a legenda, para o Partido dos Trabalhadores.

${ }^{12}$ MAGAlHÃES, José Luiz Quadros de. Direito constitucional. Belo Horizonte: Mandamentos, 2006. p. 40. 
participação popular, propiciando uma abertura dos canais participativos ${ }^{13}$ superando a barreira existente entre Estado e Sociedade Civil.

No Brasil, observamos a busca de maior descentralização e fortalecimento do poder local integrado em uma federação. É importante ressaltar que não basta descentralizar, é fundamental que o processo de descentralização leve em consideração a democracia participativa local e busque um desenvolvimento territorial equilibrado, reduzindo as desigualdades sociais e regionais. Para que isso ocorra é necessária a correta distribuição de competências entre as diversas esferas de poder no território, desde a União, passando pelos Estados - Membros, chegando aos municípios. As esferas de coordenação de políticas macro de desenvolvimento equilibrado têm de permanecer com os entes territoriais maiores, que, poderão, dessa forma, produzir o equilíbrio por meio de políticas de compensações tributárias para as diferentes realidades regionais e municipais. ${ }^{14}$

Nesse passo, o Orçamento Participativo de Porto Alegre é um exemplo bem sucedido de abertura da dimensão participativa direta dos cidadãos na alocação dos recursos públicos ${ }^{15}$.

A experiência dos Orçamentos Participativos em Porto Alegre teve início com a vitória da frente popular nas eleições municipais de 1988, composta pela coligação dos Partidos dos Trabalhadores e pelo ex Partido Comunista Brasileiro.

13 "Essa participação popular desejada que resulte em decisão, mais democracia e controle social efetivo ocorrerá de maneira efetiva e eficiente, justamente, no poder local.” MAGALHÃES, José Luiz Quadros de. Direito constitucional. Belo Horizonte: Mandamentos, 2006. v. 3. p. 40.

${ }^{14}$ MAGAlHÃES, José Luiz Quadros de. Direito constitucional. Belo Horizonte: Mandamentos, 2006. v. 3. p. 40-41.

15 "Através do Orçamento Participativo, desenvolvido durante 16 anos, a cidade de Porto Alegre é considerada internacionalmente um exemplo de oposição ao modelo neoliberal. Uma parcela significativa do seu orçamento é subordinada a um intenso processo de discussão e deliberação, no qual a população participa e decide sobre os projetos de investimento público da cidade. Se em 1988, em função do alto endividamento, apenas $2 \%$ do orçamento estavam disponíveis para investimentos, em 2003 estes passaram a somar $20 \%$ dos recursos, cuja destinação foi decidida diretamente pela população, cuja participação vem crescendo progressivamente e constitui um processo de construção da consciência política. Os cidadãos porto-alegrenses, entretanto, não se limitaram a decidir sobre a distribuição de recursos disponíveis pela arrecadação do município. O grande 
Nessa vereda, a experiência dos Orçamentos Participativos passou a embasar a administração municipal de Porto Alegre, passando por diversos conflitos, contradições e sucessos ${ }^{16}$.

Os Orçamentos Participativos foram se fortalecendo ${ }^{17}$ através do entrelaçamento entre os detentores do poder político e as organizações comunitárias municipais que já se articulavam desde a década de oitenta, visando melhorias sociais por meio de espaços públicos de discussão com o fim de implementar políticas públicas. Portanto, sua criação está baseada na interação entre a sociedade civil e o Estado.

É bastante claro que sem a contribuição decisiva da administração do Partido dos Trabalhadores na implementação da proposta ela não haveria se tornado realidade; mas é igualmente correto afirmar que a ausência do termo orçamento na proposta de governo do PT para a prefeitura de Porto Alegre demonstra que a identificação do tema orçamento foi obra do movimento comunitário. ${ }^{1817}$

capital foi taxado de impostos, de forma que o orçamento foi, gradativamente, aumentando sem que houvesse um maior endividamento e sem o abandono por parte das grandes empresas e investimentos - como constantemente vem sendo apregoado mundo afora. Há mais de dez anos Porto Alegre é, entre as capitais brasileiras, a cidade com a maior qualidade de vida e ocupa o segundo lugar entre as que mais atraem investimentos. A ressonância internacional da experiência de democracia direta fez de Porto Alegre a sede do Fórum Social Mundial em 2001, 2002, 2003 e 2005, como referência mundial dos movimentos críticos à globalização neoliberal e contraponto ao Fórum Econômico Mundial de Davos." ANDROLI, Antônio Inácio. O Orçamento participativo de Porto Alegre: um exemplo para a Alemanha? Revista Espaço Acadêmico, Porto Alegre, ano 4, n. 43, p. 1, dez. 2004.

16 "É nesse contexto que, a partir do final dos anos 1980, ganha visibilidade nacional a política de Orçamento Participativo com a experiência de Porto Alegre (Fedozzi, 1996). Essa prática logo se espalhou para diversas capitais, atingindo tanto as chamadas administrações populares, capitaneadas pelo Partido dos Trabalhadores - Belo Horizonte, Vitória, Brasília, Belém -, quanto as grandes metrópoles governadas por outros partidos de diferentes tendências, como Salvador e Recife". AZEVEDO, Sérgio de. Os desafios para o exercício da cidadania política nas sociedades modernas. In: SEMINÁRIO CIDADE, DEMOCRACIA E JUSTIÇA SOCIAL. 2003, Rio de Janeiro. Anais... Rio de janeiro, 2003. p. 2.

${ }^{17}$ AVRITZER, Leonardo. Sociedade civil, esfera pública e poder local: uma análise do orçamento participativo em Belo Horizonte e Porto Alegre. Relatório Final do Projeto Civil Society and Democratic Governance, 2000b.

${ }^{18}$ ANDROLI, Antônio Inácio. O orçamento participativo de Porto Alegre: um exemplo para a Alemanha? Revista Espaço Acadêmico, Porto Alegre, ano 4, n. 43, dez. 2004. p. 3. 
Essa ideia de implementação de um processo coletivo e público de discussão e formulação do orçamento municipal veio, entretanto, sendo construída na prática, e sofrendo críticas, crises, ressignificações e alterações.

A cidade de Porto Alegre foi dividida em dezesseis regiões e foram definidos fóruns temáticos, geralmente em torno de seis como: saúde e assistência social; educação; cultura e lazer; desenvolvimento econômico e tributação; organização da cidade, desenvolvimento urbano e meio ambiente; transporte e circulação.

Segundo Antônio Inácio Andriolli ${ }^{19}$ os critérios para debates nos fóruns temáticos são os seguintes: "a) carência de infraestrutura; b) número de moradores; c) prioridade escolhida diretamente pela população".

No início a administração porto-alegrense passou por diversas dificuldades e problemas para a implantação dos orçamentos participativos. Primeiro, a divisão municipal em quatro regiões; segundo o fato da administração municipal ter assumido uma prefeitura em grave crise financeira, ${ }^{20} \mathrm{impossibilitando} \mathrm{que} \mathrm{muitas}$ obras discutidas fossem realmente efetivadas pelo poder público. Tal situação gerou o descrédito da população.

Basicamente, os Orçamentos Participativos possuem o seguinte procedimento:

Embora variando bastante para cada cidade, os diferentes modelos do Orçamento Participativo possuem alguns pontos comuns. Normalmente, o processo tem início com a realização de assembléias que congregam moradores de bairros próximos localizados em cada uma das regiões tradicionais da cidade. Os moradores são então informados sobre a composição do orçamento municipal e o montante

${ }^{19}$ FEDOZZI, L. J. Do patrimonialismo à cidadania participação popular na gestão municipal: o caso do orçamento participativo de Porto Alegre. 1996. 313 f. Dissertação (Mestrado em Sociologia)-Curso de Pós-Graduação em Sociologia, Universidade Federal do Rio Grande do Sul, Porto Alegre, 1996.

${ }^{20}$ AZEVEDO, Sérgio de. Os desafios para o exercício da cidadania política nas sociedades modernas. In: SEMINÁRIO CIDADE, DEMOCRACIA E JUSTIÇA SOCIAL, 2003, Rio de Janeiro. Anais... Rio de janeiro, 2003. p.3. 
de recursos disponível, e são realizadas uma ou mais assembléias para a seleção das demandas da sub-região e a escolha dos delegados que irão defendê-las no Fórum Regional. Na seqüência do processo, os delegados eleitos nessas assembléias participam do Fórum Regional, em que definem uma ordem de prioridades das demandas de serviços e obras a serem encaminhadas ao Fórum Municipal. $\mathrm{Na}$ instância regional, em muitos casos, é ainda realizada a escolha dos membros que irão representar cada região na Comissão ou Grupo encarregado do acompanhamento e fiscalização do Orçamento Participativo, por ocasião da implementação das obras e serviços. Por fim, o Orçamento Participativo é consolidado no Fórum Municipal na versão que será encaminhada à Câmara dos Vereadores para apreciação dos parlamentares. Pode-se dizer que o Fórum Municipal é um evento de cunho político, no qual culmina todo o processo. Após o encaminhamento oficial da proposta ao legislativo municipal, há diferentes tipos de mobilização para que a população potencialmente beneficiada atue na Câmara de Vereadores, a fim de garantir a aprovação da maior parte das obras e serviços pactuados durante o processo do Orçamento Participativo. ${ }^{21}$

\section{Um dos entraves à consolidação dos Orçamentos Participativos foi o fato de} eles atingirem as práticas discricionárias de alocação de recursos, combinando características democráticas e inovadoras de maneira a barrar práticas clientelistas ${ }^{22}$.

21 "Do mesmo modo, há também outros desafios a serem enfrentados: a complexidade do atual processo público de licitação que atrasa as obras; a baixa participação da "classe média" (apesar dos avanços nos dois últimos anos), que se sente sem condições de disputar benfeitorias com os setores populares (maiores em número e em níveis de carência); a dificuldade de aprovação de projetos estratégicos de longo prazo no lugar de inúmeras pequenas obras pulverizadas (muitas prefeituras optaram por não incluir os projetos estratégicos no Orçamento Participativo); e, por fim, a questão da pequena participação dos setores populares de mais alto nível de pobreza (e de baixa capacidade organizacional), dificultando que se atinja o "fundo do tacho". AZEVEDO, Sérgio de. Os desafios para o exercício da cidadania política nas sociedades modernas. In: SEMINÁRIO CIDADE, DEMOCRACIA E JUSTIÇA SOCIAL, 2003, Rio de Janeiro. Anais... Rio de janeiro, 2003. p. 5-6.

22 "Por fim, merece registro o impacto modernizador produzido pelo Orçamento Participativo sobre as diferentes agências públicas municipais responsáveis pelas obras e prestação de serviços sociais. Em que pesem as iniciativas convencionais de modernização implementadas (reformas administrativas, reformulação dos organogramas etc.), verificou-se um significativo consenso de que as transformações e o aumento da 
Além disso, outro obstáculo aos Orçamentos Participativos é a vinculação orçamentária, ou seja, a falta de recursos públicos para a implementação das obras decididas e deliberadas pela população.

Tais conflitos iniciais foram positivos, pois evitaram o estabelecimento de um modelo imposto ou previsível, instituindo uma nova forma de administração com a coparticipação social a partir de elementos da realidade, proporcionando um aumento da eficiência administrativa, maior justiça na alocação dos recursos, e maior capacidade participativa e de controle social.

Posteriormente, os Orçamentos Participativos poderiam propiciar a realização da reforma tributária para obtenção de recursos destinados às políticas públicas; a reestruturação interna da administração; uma nova divisão de regiões da cidade baseada em critério sócio territorial; a substituição da lógica da concentração dos investimentos pela distribuição por setor de investimento como saneamento, pavimentação etc, de maneira a reformular os critérios de distribuição dos recursos; a instituição dos Conselhos de Orçamentos Participativos, conselhos e assembléias regionais.

Nesse sentido, passados momentos de crise, os Orçamentos Participativos propiciaram uma retomada dos investimentos, um aperfeiçoamento dos métodos de distribuição de recursos, a construção de uma dinâmica institucional participativa, resgatando a credibilidade popular nessa forma de participação deliberativa.

Assim, os Orçamentos Participativos ${ }^{23}$ são um meio de fortalecimento do poder local e de resgate da democracia social propiciando a participação efetiva do

eficiência daqueles órgãos deveriam ser, em grande parte, debitados à pressão e à maior capacidade de fiscalização dos cidadãos propiciadas pelos instrumentos disponibilizados pelo Orçamento Participativo." AZEVEDO, Sérgio de. Os desafios para o exercício da cidadania política nas sociedades modernas. In: SEMINÁRIO CIDADE, DEMOCRACIA E JUSTIÇA SOCIAL, 2003. Rio de Janeiro. Anais... Rio de janeiro, 2003, p. 4-5.

23 "Ao mesmo tempo que o OP envolve todos esses problemas práticos, ele tem suscitado um conjunto de questões no interior de diferentes embates teóricos: o debate entre a sociedade civil e a democracia, o debate sobre o aprofundamento da democracia e o debate sobre o desenho institucional. Em todos os casos, mais uma vez se coloca a seguinte questão: sendo Porto Alegre uma cidade com tradição associativa longa em termos de Brasil, seria possível pensar o OP em lugares sem essa tradição? Outra questão que aparece 
povo como cidadãos, a descentralização do poder, o fortalecimento dos Estados e, especialmente, os Municípios, de maneira a criar canais de participação popular a partir do poder local.

A participação popular na elaboração da proposta orçamentária conduz a um maior engajamento político da população, ou seja, mitiga ou até mesmo inibe a ocorrência do fenômeno do refluxo, da repulsa da população à política.

Além disso, com a participação popular na elaboração dos orçamentos o Poder Legislativo acaba tendo mais destaque tendo em vista que, acatando a opinião pública, adquire a confiança popular, aumentando o crédito da população em seus agentes políticos.

Nesse sentido, por meio da participação direta, a população tem a possibilidade de exercer o controle direto da Administração Pública, além de opinar e permitir a efetivação das prioridades nos investimentos oriundos dos cofres públicos em benefício de toda a coletividade.

Nessa esteira, a exemplo dos Orçamentos Participativos em Porto Alegre ${ }^{24}$, é necessária a criação de instituições, conselhos, que canalizem o direito à participação direta na gestão pública, tendo em vista que a participação popular origina uma produção dialética e eficaz.

Diante de um panorama global de interesses, há o aumento dos debates, possibilitando uma tomada de decisão conjunta sobre a alocação de recursos

constantemente no debate é: a quais elementos devemos atribuir a especificidade da experiência Porto Alegrense? Ao Idesenho institucional, à presença de um partido com uma proposta de ampliação da democracia ou a um forte movimento comunitário existente na cidade? Essas questões, se tornaram tema de um profundo debate teórico." AVRITER, Leonardo. $O$ orçamento participativo e a teoria democrática: um balanço crítico. Rede Brasileira de Orçamento Participativo, 2010. Disponível em:<http://www. pbh.gov.br/redebrasileiraop/html/biblioteca/LeonardoAvritzer_port.pdf $>$. Acesso em: 11 jun. 2010.

${ }^{24}$ SOARES, Mário Lúcio Quintão. Teoria do Estado. Belo Horizonte: Del Rey, 2001. p. 328. 
públicos, de acordo com as prioridades da maioria da população de modo a gerar políticas públicas mais eficazes.

Em suma, a sociedade do risco imprime constitucionalmente a necessidade de participação dos cidadãos, o aumento das garantias protetivas contra o Estado e os detentores do poder, bem como a transparência dos procedimentos e das funções públicas. Nesse ponto, os Orçamentos Participativos cumprem o seu papel, servindo de mecanismo de deliberação e transparência da efetivação das políticas públicas.

Nesse passo, portanto, é necessário repensar as estruturas administrativas, de maneira a adaptá-las aos princípios constitucionais e democráticos, e os Orçamentos Participativos trazem essa proposta.

Infelizmente, em nosso modelo de organização administrativa ocorre ainda a centralização dos processos de decisão e de construção de programas de ação, o que leva a desconsiderar as realidades locais. É necessário acontecer o oposto disso, as ações administrativas devem ser pautadas em um planejamento moderado, proporcional, de maneira a se adequarem às comunidades nas quais se aplicam.

A implementação do princípio da participação popular no governo, consoante o Estado Democrático de Direito, é um remédio a ser aplicado para corrigir essa ausência de diálogo de uma sociedade oligárquica e patrimonialista. Daí sobrelevar-se a importância da educação política como condição inarredável para uma cidadania ativa numa sociedade republicana e democrática. ${ }^{25}$

Com o princípio da representação verifica-se o distanciamento exacerbado entre a esfera política e a esfera pessoal, e, portanto, é necessária uma integração sociopolítica deliberativa, aproximando o cidadão da política.

Nesse sentido, o modelo do Orçamento Participativo de Porto Alegre possibilitou a objetividade e a clareza das decisões; a transparência orçamentária a

${ }^{25}$ OHLWEILER, Leonel Pires. Políticas públicas e controle jurisdicional: uma análise hermenêutica à luz do Estado democrático de direito. In: SARLET, Ingo Wolfgang; TIMM, Luciano Benetti. (Org). Direitos fundamentais, orçamento e "reserva do possível". Porto Alegre: Livraria do Advogado, 2008. p. 336. 
toda a população e a efetiva implementação de todas as decisões tomadas com a participação popular.

No entanto, para materializar políticas públicas é imperioso que os governos e a própria sociedade assumam-se como co-responsáveis por este processo e tenham a capacidade de construir espaços públicos de aprendizagem social, quer dizer, um planejamento temporalizado, mas preparado para o acontecer ou os fracassos possíveis da democracia. ${ }^{26}$

Consoante o entendimento de Mário Lúcio Quintão Soares ${ }^{27}$, “[...] esta nova cidadania, erigida pelo novo paradigma, consiste na capacidade de participar no exercício do poder político e da gestão dos negócios da comunidade. As formas desse exercício definem os meios diretos ou não de participação dos cidadãos".

Segundo Rodolfo Viana Pereira ${ }^{28}$, "a democratização do processo decisório serve a dois propósitos fundamentais: incrementar a probabilidade de acerto na tomada de decisões e compartilhar com a sociedade a responsabilidade pelas opções deliberadas."

Nesse sentido, a participação serviria como um mecanismo de atribuição de responsabilidade e promoção de aceitabilidade, de maneira que essa abertura

${ }^{26}$ SOARES, Mário Lúcio Quintão. Teoria do Estado. Belo Horizonte: Del Rey, 2001. p. 307.

${ }^{27}$ PEREIRA, Rodolfo Viana. Direito constitucional democrático. Rio de Janeiro: Lúmen Júris, 2008. p. 157.

${ }^{28}$ A implementação do orçamento participativo em Belo Horizonte ocorreu no ano de 1994, na qual houve a divisão das regiões administrativas em sub-regiões, sendo criadas assembléias participativas nessas sub-regiões. Primeiramente foi realizado um trabalho informativo, conscientizando os participantes sobre o orçamento municipal, os gastos da Prefeitura. Em uma segunda fase foram feitos debates sobre as prioridades nas respectivas realidades sociais regionais, sendo distribuídos formulários para levantamento dessas prioridades. Em uma terceira fase, houve o recebimento dos formulários preenchidos e a eleição das três áreas de interesse social. Foram realizadas caravanas, fóruns regionais e encontros municipais de prioridades. Além disso, em 2006, a Prefeitura Municipal de Belo Horizonte foi a primeira cidade a implantar o Orçamento Participativo Digital proporcionando a ampliação da participação e do debate via internet, um modelo sofisticado de participação. Ao longo dos últimos quinze anos, os Orçamentos Participativos geraram a conclusão de aproximadamente mil empreendimentos. 
fortaleceria a formação de opinião bem como a divisão alargada da responsabilidade das decisões no caso de resultados desfavoráveis.

É evidente a contribuição positiva dos movimentos sociais para o fortalecimento das práticas democráticas, pois eles são atores que canalizam as principais preocupações e necessidades da população: $1^{\circ}$ ) facilitam a criação de elos para o entendimento mútuo; $2^{\circ}$ ) promovem o reconhecimento, a reconstrução e a proteção de identidades coletivas marginalizadas; $3^{\circ}$ ) facilitam a melhor representação dos interesses; $4^{\circ}$ ) promovem a abertura dos canais participativos; $5^{\circ}$ ) viabilizam a externalização dos dissensos, ou seja, a prática de tais movimentos tem como efeito direto tornar públicas as diversidades de interesses e as suas complexidades; e $6^{\circ}$ ) exponenciam os índices de eficácia das funções de fiscalização e controle do poder.

A efetividade da implementação de políticas públicas ocorre apenas com a integração entre o cidadão e o Poder Público de maneira a fazer os planos construídos, acontecerem, exigindo certas estratégias como debates para aspirar às necessidades da comunidade, quebrando o "tabu" de uma organização administrativa clássica hierárquica, do administrador autoritário, ditatorial.Portanto, essa participação popular na elaboração do orçamento público tem sido adotada com sucesso em Porto Alegre e vem sendo implementada com sucesso em Belo Horizonte ${ }^{29}$, em Recife, ${ }^{30}$ em Fortaleza, a qual, como já afirmado anteriormente, consiste na sujeição ao debate e à escolha popular da destinação de parcelas do orçamento público municipal.

29 "Algumas evidências destacadas no Governo da Frente Popular em Recife permitem concluir sobre as possibilidades concretas de uma administração progressistaimplementar políticas públicas capazes de redirecionar investimentos estruturadores em benefício dos setores sociais tradicionalmente excluídos, sem deixar de criar uma imagem favorável junto a parcelas mais amplas da opinião pública. Nesta direção, dois aspectos devem ser destacados. O primeiro, no campo político, implica na necessidade de os governos se apoiarem em um leque de alianças o mais amplo possível que aponte para a sociedade a solidez das mudanças pretendidas. O segundo, também de fundamental importância, é representado pela presença dos movimentos sociais organizados na administração. $\mathrm{O}$ significado da presença destes novos atores na definição das prioridades do governo e na fiscalização das atividades públicas expressa tanto o reconhecimento de novos interesses sociais no jogo político quanto a possibilidade real de impactar, por fora, a inércia 
O Programa de Orçamento Participativo da Prefeitura do Recife ${ }^{31}$ foi selecionado pelo Centro de Estudos em Administração Pública e Governo (CEAPG), da Fundação Getúlio Vargas de São Paulo (FGV-EAESP) para concorrer ao Prêmio Reinhard Mohn 2011.

Além disso, após cinco anos da existência dos Orçamentos Participativos em Fortaleza, a partir de 2010 as assembleias deliberativas passaram a ocorrer em dois momentos: uma etapa eletiva e uma etapa decisiva. Na etapa eletiva, é fornecida aos cidadãos a possibilidade de priorizar as propostas ou os serviços de acordo com a região ou segmento social. Já na etapa decisiva, com base no orçamento do município e no custo de cada obra ou serviço priorizado, os participantes da assembleia definirão as ações a serem realizadas pela Prefeitura, o que anteriormente era feito pelas rodadas de negociações entre os gestores municipais e o Conselho do Orçamento Participativo.

Todavia, apesar dessas experiências vitoriosas, o exemplo de Porto Alegre encontra dificuldade em ser adotado em outros Municípios e Estados da Federação diante da possível ausência de preparo técnico da população local, da necessidade de fortalecimento da integração entre o povo e os membros do legislativo municipal e até mesmo devido à ausência de vinculação entre o deliberado nos orçamentos participativos e a decisão do administrador público municipal.

\footnotetext{
da máquina administrativa." SOARES, José Arlindo; SOLER, Salvador. Poder local e participação popular. Rio de Janeiro: Rio Fundo, 1992. p. 55-56.

30 "A partir deste ano, a população se reunirá previamente, em grupos de no mínimo dez pessoas, para indicar duas obras e ações. Em seguida, na plenária regional, os participantes votarão em duas das ações credenciadas na etapa anterior, gerando uma lista com as dez prioridades de cada microrregião. As plenárias intermediárias não acontecerão mais. Quem não tiver comparecido às plenárias regionais terá mais oportunidades de contribuir com o processo do OP: em cada microrregião, urnas eletrônicas serão colocadas em locais estratégicos, para que as pessoas possam votar numa das 10 obras mais bem colocadas nas plenárias regionais. E a votação poderá também ser feita pela Internet, no site da Prefeitura do Recife." Disponível em: <http://www.recife.pe.gov.br/op/como.php $>$. Acesso em: 18 mar. 2011.

${ }^{31}$ MÜLLER, Friedrich. Quem é o povo? 4. ed. São Paulo: RT, 2008. p. 61.
} 
Dessa forma, na democracia, a participação do cidadão no poder configura-se pela efetiva atuação em movimentos sociais em suas comunidades, concretizando a cidadania sob o prisma legal.

Para Friedrich Muller (2008) povo pode ser conceituado sob dois ângulos: um, o povo destinatário das prestações civilizatórias do Estado e o povo participante, ou seja, o povo ativo que faz a diferença, que exerce o seu papel de cidadão, se engajando politicamente de forma consciente e ativa.

A função do "povo", que um Estado invoca, consiste sempre em legitimá-lo. A democracia é dispositivo de normas especialmente exigente, que diz respeito a todas as pessoas no seu âmbito de "demos" de categorias distintas (enquanto povo ativo, povo como instância de atribuição ou ainda povo - destinatário) e graus distintos. A distinção entre direitos de cidadania e direitos humanos não é apenas diferencial: ela é relevante com vistas ao sistema. Não somente as liberdades civis, mas também os direitos humanos enquanto realizados são imprescindíveis para uma democracia legítima. ${ }^{32}$

O Orçamento Participativo permite uma melhora na organização dos orçamentos de acordo com os critérios e prioridades definidos pela população e a verificação da probidade administrativa no que tange à alocação e destinação dos recursos públicos.

A experiência de Porto Alegre tem chamado a atenção pelas suas características fundamentais: democracia, equidade, solidariedade, eficiência. Tais características teriam melhorado a qualidade de vida da população de baixa renda devido principalmente ao efeito redistributivo dos orçamentos. Portanto, houve uma extensão do processo democrático para os setores organizados da população pobre da cidade, melhorando as condições de vida da população.

${ }^{32}$ Em regiões de menor renda o número de obras realizadas pelo governo é maior e em regiões de menor renda o número de obras é menor. Além disso, o efeito redistributivo pode ser verificado na expansão dos serviços públicos em áreas mais carentes onde não eram oferecidos e em locais de habitação recente. 
O governo e a sociedade civil estabeleceram no Município de Porto Alegre uma administração compartilhada, havendo entendimento mútuo entre as esferas públicas e privadas, entre o governo municipal e a sociedade civil. Os Orçamentos Participativos abrangem os dois segmentos, gerando resultados positivos para a sociedade como um todo.

Há quem questione se os orçamentos participativos possuem efeitos redistributivos $^{33}$ e se foram proporcionados pela sociedade civil ou pela administração.

O caráter redistributivo do orçamento participativo foi um dos objetivos centrais de sua instituição, visando proporcionar uma diminuição da desigualdade social e regional. Desde a sua implantação, as regiões mais pobres foram a que receberam o maior número de investimentos per capita.

O único problema a ser solucionado é o fato de que regiões pobres, porém muito populosas ainda sofrem com a falta de políticas públicas mesmo com o efeito redistributivo dos orçamentos participativos, sendo este um ponto que necessita de maior análise governamental.

Nesse sentido, verifica-se que há limites na capacidade dos Orçamentos Participativos em resolver os problemas da população em regiões de baixa renda e populosa. Tais limites estão relacionados com a capacidade financeira dos municípios para fazer frente aos problemas que atingem as cidades do país.

Nesse passo, a adaptação dos orçamentos participativos em outros municípios deve objetivar aumentar o efeito redistributivo dos gastos públicos com a

\footnotetext{
${ }^{33} \mathrm{O}$ alargamento desses espaços alternativos para debates bem como o incentivo das informações fornecidas pelos meios de comunicação em massa podem aumentar o nível de legitimidade, de participação popular. O povo necessita de espaço para a sua atuação, tendo em vista que são atores sociais e políticos por natureza que necessitam de palcos para atuarem e não serem tratados como meros expectadores. Nesse ponto, é necessário a devolução ao povo daquilo que está nas mãos dos governantes com a implementação de formas autônomas de participação popular, certa inversão, logicamente mitigada, do modelo de Rousseau.
} 
adoção de programas específicos para efetivar políticas públicas mediante a coparticipação da população.

Os Orçamentos Participativos propiciam a inclusão da efetiva participação da população na esfera pública com o alargamento do foro tradicional da política (ou seja, os debates e as tomadas de decisões fugiriam dos foros tradicionais para alcançar outros âmbitos mais populares, como fóruns, debates via internet, associações criadas com essa finalidade, etc), sendo instrumentos de abertura dos canais comunicativos ${ }^{34} \mathrm{e}$ deliberativos à população.

Ademais, cabe ressaltar o entendimento de Luciano Benetti $\operatorname{Timm}^{35}$ e de Ana Paula de Barcellos ${ }^{36}$ de que os recursos orçamentários obtidos por meio da tributação, incluindo a abertura de créditos adicionais, devem ser empregados pelo

34 TIMM, Luciano Benetti. Qual a maneira mais eficiente de prover direitos fundamentais: uma perspectiva de direito e economia? In: SARLET, Ingo Wolfgang; TIMM, Luciano Benetti (Org). Direitos fundamentais, orçamento e "reserva do possível". Porto Alegre: Livraria do Advogado, 2008. p. 67.

${ }^{35}$ BARCELlOS, Ana Paula de. Constitucionalização das políticas públicas em matéria de direitos fundamentais: o controle político-social e o controle jurídico no espaço democrático. In: SARLET, Ingo Wolfgang; TIMM, Luciano Benetti (Org.). Direitos fundamentais, orçamento e "reserva do possível". Porto Alegre: Livraria do Advogado, 2008. p. 146.

${ }^{36}$ Sudeste: Aracruz (Espírito Santo); Araraquara (São Paulo); Belo Horizonte (Minas Gerais); Botelhos (Minas Gerais); Cachoeiro do Itapemirim (Espírito Santo); Cariacica (Espírito Santo); Congonhas (Minas Gerais); Contagem (Minas Gerais); Diadema (São Paulo); Francisco Morato (São Paulo); Guarulhos (São Paulo); Maricá - (Rio de Janeiro); Monte Alto (São Paulo); Montes Claros (Minas Gerais) ; Nova Lima (Minas Gerais); Osasco (São Paulo); Santo André (São Paulo); São Bernardo do Campo (São Paulo); São Carlos (São Paulo); São Vicente (São Paulo); Serra (Espírito Santo); Suzano (São Paulo); Várzea Paulista (São Paulo); Viana (Espírito Santo); Vitória (Espírito Santo); Região Nordeste: Anadia (Alagoas); Caaporã - (Paraíba); Cajazeiras - (Paraíba); Campina Grande (Paraíba); Crateus - (Ceará); D. Inês - (Paraíba); Fortaleza (Ceará); João Pessoa (Paraíba); Patos - (Paraíba); Picuí - (Paraíba); Pombal (Paraíba); Recife (Pernambuco); Região Norte: Manaus (Amazonas); Região Sul: Bagé (Rio Grande do Sul); Bento Gonçalves (Rio Grande do Sul); Canoas (Rio Grande do Sul); Caxias do Sul (Rio Grande do Sul); Campo Largo (Paraná); Esteio (Rio Grande do Sul); Garibaldi (Rio Grande do Sul); Gravataí (Rio Grande do Sul); Joinville (Santa Catarina); Nova Hartz (Rio Grande do Sul); Porto Alegre (Rio Grande do Sul); Santa Maria (Rio Grande do Sul) Santa Rosa (Rio Grande do Sul); São Leopoldo (Rio Grande do Sul); Sapucaia do Sul (Rio Grande do Sul). Há cidades que estão em processo de adesão aos orçamentos participativos: Região Sudeste: 
Poder Público de modo mais eficiente para que possa atingir o maior número de demandas da população, cumprindo as metas fixadas.

Com a participação popular no direcionamento dos investimentos em políticas públicas e sociais, as prioridades locais podem ser atendidas pelo administrador público de maneira a, efetivamente, melhorar a qualidade da prestação dos direitos fundamentais sociais.

Portanto, o exemplo de Porto Alegre pode ser adotado em todos os municípios brasileiros, pois a população mobilizada é capaz de, por meio da coparticipação na gestão do orçamento público, pressionar governos no sentido da implantação efetiva das políticas públicas e assim minimizar as desigualdades regionais.

Atualmente, diversos municípios brasileiros adotaram os orçamentos participativos $^{37}$ na tentativa de fortalecer o poder local. Portanto, o município de Porto Alegre é um exemplo, mas não é o único que aponta nessa direção. Há trabalhos desenvolvidos em Belo Horizonte, São Paulo e Recife que possuem potenciais semelhantes acentuando elementos participativos e representativos na cultura política e estabelecendo uma sinergia democratizante com os setores organizados da sociedade.

Campinas - (São Paulo); Juatuba - (Minas Gerais); Linhares - (Espírito Santo); Ouro Branco - (Minas Gerais); Ouro Preto - (Minas Gerais); Taboão da Serra - (São Paulo); Região Nordeste: Barbalha - (Ceará); Cascavel - (Ceará); Natal - (Rio Grande do Norte); Olinda - (Pernambuco); Santarém - (Paraíba); Serrinha - (Bahia); Região Sul ; Biguaçu - (Santa Catarina); Capão da Canoa - (Rio Grande do Sul); Cruz Alta - (Rio Grande do Sul); Dois Irmãos - (Rio Grande do Sul); Erechim - (Rio Grande do Sul). Disponível em: <http://www.pbh.gov.br/redebrasileiraop/html/cid_part.htm>. Acesso em: 18 mar. 2011.

${ }^{37} \mathrm{O}$ Equal é um projeto apoiado pela iniciativa comunitária tendo como objetivo disseminar o tema e a metodologia do Orçamento Participativo a nível nacional. Em termos específicos isso significa: a) apoiar a adoção dos orçamentos participativos por parte das autarquias portuguesas; b) capacitar teórica e metodologicamente os diferentes intervenientes no desenvolvimento de processos de orçamentos participativos; c) criar instrumentos de apoio à implementação, desenvolvimento e monitorização e avaliação desses processos; d) promover a partilha de experiências e as relações em rede entre as autarquias promotoras dos orçamentos participativos. Disponível em: <http://www.opportugal.org/index.php>. Acesso em 11. jun. 2010.

${ }^{37} \mathrm{Na}$ Espanha, os orçamentos participativos são chamados de "pressupostos participativos". Eles são uma ferramenta de participação e gestão da cidade, mediante a qual os cidadãos podem propor e decidir sobre o destino e parte dos recursos municipais. Na Espanha, as 
Além disso, diante da extrema importância dos orçamentos participativos como um meio relevante de participação popular, a experiência bem sucedida de Porto Alegre percorreu o mundo atingindo países como Portugal, ${ }^{38}$ Espanha, ${ }^{39}$ Itália, Chile, ${ }^{40}$ República Dominicana ${ }^{41}$, ganhando novas formas, como o ocorrido na Itália ${ }^{42}$.

experiências mais significativas até agora se desenvolveram em cidades como Sevilla, Córdoba, Albacete, San Sebastián, Málaga, Jerez, Getafe, Petrer, Puente Genil, Cabezas de San Juan, Sabadell, Leganés, Torreperogil, Puerto Real, Torrellano, Novelda e Santa Cristina d'Aro dentre outras. Disponível em: <http://www.presupuestosparticipativos. com/inicio/_C3VTDDatmVEmYYYsYdvRIkI5Hq8tUlWq>. Acesso em: 11 jun. 2010.

${ }^{39}$ No Chile também podem ser verificados os orçamentos participativos com algumas inovações. No dia primeiro de junho de 2010 foram criados os "Pressupostos Participativos Escolares, sendo uma iniciativa municipal que busca promover a participação ativa de todos os alunos e alunas de escolas, inclusive colégios para especiais, de modo a garantir o acesso de toda a comunidade escolar. Os pressupostos participativos escolares buscam incentivar a cultura cívica entre os estudantes promovendo debates sobre iniciativas e projetos na área escolar". Disponível em: <http://www.presupuestoparticipativo.cl/>. Acesso em: 11 jun. 2010.

${ }^{40}$ Uma adaptação dos Orçamentos Participativos é vista na Federação Dominicana de Municípios na República Dominicana onde há o incentivo a formação de vários fóruns e debates locais entre a população e as autoridades. Disponível em: $<$ http://www.fedomu. org.do/index.html>. Acesso em: 11 jun. 2010.

${ }^{41}$ A Rede Novo Município é um espaço que promove a divulgação dos processos participativos em Itália. Disponibiliza um fórum e uma agenda, documentos e notícias relacionados com a gestão pública e democracia participativa. A partir do Fórum Social Mundial em Porto Alegre em 2002, iniciou um processo de reconhecimento por muitas das instituições locais, das associações e pesquisadores na Itália, a possibilidade real de uma forma alternativa de democracia que lhe permite pôr em jogo e qual o valor dos ativos, cultural e territorial das comunidades locais em risco de serem submersos pela maré da globalização pilar intervencionista e de negócios. Para apoiar este processo, através da partilha de diretrizes para a sua tradução em políticas locais e sociais, 08 de novembro de 2003, ele formou a Rede da Câmara Municipal do Novo Município, na tentativa de transmitir, de forma estável da associação, os casos de renovação e extensão dinâmica do processo de decisão de diferentes setores da sociedade civil, as áreas institucionais mais sensíveis à questão da audiência, a constante representada por estudiosos e pesquisadores em torno das questões de capacitação das comunidades locais na gestão do território. Nos anos que se passaram desde então, a rede tem ajudado a produzir uma série de profundas transformações das estruturas e os temas de governo local (e outros), alguns dos seus melhores resultados são coletados agora no nosso arquivo de Melhores Práticas. Disponível em: <http://www.nuovomunicipio.org/>. Acesso em: 11 jun. 2010.

42 SILVA, Marcelo Kunrath. Cidadania e exclusão: os movimentos sociais urbanos e a experiência de participação na gestão municipal de Porto Alegre. Porto Alegre: UFRGS, 2002. p. 52. 
Portanto, a participação popular deve apresentar conexão com a representação, apontando na direção da vontade política dos governantes e na superposição de desenhos institucionais participativos na tentativa de democratizar a democracia em diversas escalas territoriais; tal situação pode ser observada nos orçamentos participativos.

\section{Críticas ao orçamento participativo}

Segundo Marcelo Kunrath Silva, “[...] um dos novos elementos que se colocam no contexto da transição política brasileira é a reorganização da sociedade civil e a emergência de novos atores e discursos dela originados" ${ }^{33}$.

O estímulo à participação popular ativa nos destinos do Estado deve ser encarado sob dois ângulos: como ideia de devolução do poder a quem de direito deve pertencer e como medida de prevenção a eventuais rupturas institucionais.

Contudo, se por um lado o Orçamento Participativo dá a possibilidade aos munícipios de ter voz ativa nas decisões sobre as políticas públicas a serem desenvolvidas pelo Executivo, com poder, inclusive, para fiscalizar a efetivação das políticas escolhidas, coloca o cidadão em uma situação de corresponsabilidade relativamente aos eventuais êxitos e fracassos da gestão pública.

$\mathrm{O}$ ato de administrar implica em construir, planejar, orçar, recorrer à série de ferramentas científicas para tomada de uma decisão. Nesse sentido, questiona-se se o povo estaria tecnicamente preparado para decidir sobre a gestão urbana.

Além disso, outro questionamento a ser feito é se o orçamento participativo não entraria em conflito com a Câmara de Vereadores e se o gestor municipal

\footnotetext{
${ }^{43}$ SOUZA, Celina. Construção e consolidação de instituições democráticas: papel do orçamento participativo. São Paulo em Perspectiva: revista da Fundação Seade, São Paulo, v. 15 , n. 4 , p. $8-9$, out./dez. 2001.
} 
estaria obrigado a cumprir com as deliberações oriundas dos orçamentos participativos.

Problemas ainda mais complexos surgem quando a participação resulta, como no caso do OP, de um programa liderado e induzido pelo governo, ou seja, é uma política que vem 'de cima"'. No entanto, a autora ressalta a existência de consenso na literatura, que "apesar dos problemas, tensões e resultados não previstos que decorrem do OP, a experiência tem se constituído em forma de acesso do cidadão ao processo decisório local. ${ }^{44}$

A Constituição Federal concede ao Legislativo a competência para votar o orçamento anual, e, por outro lado também prevê que tais municípios são autônomos para "[...] legislar sobre assuntos de interesse local" (art. 30, I) e " [...] promover, no que couber, adequado ordenamento territorial, mediante planejamento e controle do uso, do parcelamento da ocupação do solo urbano" (art. 30, VIII), ou seja, os municípios são autônomos para cuidarem de seus interesses da maneira mais adequada e de acordo com os interesses municipais.

Portanto, não haveria conflito de interesses, pois o art. 29, XII da Constituição Federal prevê a "[...] cooperação das associações representativas no planejamento municipal” (art. 29, XII). Por isso, o argumento de que o Orçamento Participativo viola competências específicas de vereadores não prospera.

Além disso, as deliberações aprovadas nas deliberações oriundas dos orçamentos participativos são formalmente apresentadas às Câmaras de Vereadores para voto e aprovação ou até mesmo apresentação de eventuais emendas.

Os Orçamentos Participativos reforçam a competência do legislativo municipal e o aproximam dos atores sociais, da população local que legitima a atuação deles, além de fiscalizar o cumprimento do que foi aprovado pela Câmara Municipal, no que tange ao orçamento anual.

${ }^{44}$ SOARES, José Arlindo. Poder local e participação popular. Rio de Janeiro: Rio Fundo, 1992. p. 88. 
Ademais, há ainda um questionamento a ser discutido: o administrador público municipal está obrigado a cumprir o que foi deliberado, decidido, pelo orçamento participativo?

A institucionalização de mecanismos de participação direta somente pode ser considerada uma conquista na medida em que se torne espaço de decisão e não só espaço de idéias. Pois no último caso, o espaço institucional configura-se como uma concessão das classes hegemônicas. Resulta ser apenas um espaço formal e inócuo, sem poder real. Pelo contrário, um espaço institucional de participação é uma conquista quando não se torna o final de uma luta, mas expressão real da relação de forças existentes na sociedade, quando a negociação configura um método e um meio das classes não hegemônicas para fazer valerem seus interesses. ${ }^{45}$

Nessa vereda, em tese, não há como estabelecer uma vinculação necessária entre o deliberado nos Orçamentos Participativos e o ato do Poder Público, sendo essa uma questão importante a ser reformulada em tal instituto para que realmente haja uma integração maior entre representantes e representados.

Restaria apenas uma dívida de ordem moral entre o administrador público municipal e a sociedade local, que, tem que ficar mais atenta, cobrar e fiscalizar o cumprimento pelo poder público do deliberado nos orçamentos participativos. Esse é um ponto que deve ser revisto no que tange à eficácia desse instituto.

\section{Considerações finais}

A Constituição Federal de 1988 tutela o sistema participativo, portanto a sociedade brasileira necessita conduzir-se com inteligência e responsabilidade no regime democrático para haver o fortalecimento, no Brasil, da participação popular.

Seguindo o entendimento de Canotilho, ao pressupor a participação igual dos cidadãos, o princípio democrático entrelaça-se com os direitos subjetivos de

${ }^{45}$ CANOTILHO, José Joaquim Gomes. Direito constitucional e teoria da constituição. Coimbra: Almedina, 2001. p. 288. 
participação e de associação que se tornam, assim, fundamentos funcionais da democracia.

Dessa forma, ao intensificar a participação direta e ativa do povo, haverá a democratização da democracia, estimulando, portanto, a mobilização social na destinação dos recursos públicos.

As escolhas políticas do administrador em relação à destinação do orçamento público deveriam ser produzidas com a oitiva do administrado, ou seja, com a participação popular, de modo a haver maior transparência e eficiência dos atos do Poder Público na destinação de verbas para a prestação dos direitos sociais.

Por fim, seguindo o modelo de Porto Alegre, constata-se a necessidade de uma Administração Pública mais ativa no sentido de empregar os recursos públicos na efetivação de políticas públicas urgentes e adequadas à realidade local, e, mediante a coparticipação popular, elaborar programas orçamentários e sociais eficazes, de maneira que a prestação dos serviços públicos possa efetivamente alcançar a população mais carente.

Ademais, pelo presente estudo, conclui-se que é necessário haver um aprofundamento da identidade popular, de maneira a possibilitar que as funções públicas sejam exercidas com maior participação dos cidadãos.

Nesse sentido, não resta dúvida de que a abertura dos canais de acesso ao Poder Público é imperiosa e urgente, sendo o orçamento participativo um instrumento de gestão e de defesa popular contra a má destinação dos recursos públicos, apesar de possuir ainda algumas máculas que devem ser sanadas, como a necessidade de vinculação do deliberado em assembleia popular e a decisão do administrador público municipal, conforme analisado anteriormente.

Os Orçamentos Participativos romperam com os paradigmas clássicos da Administração Pública e proporcionaram a integração da sociedade no processo de tomada de decisão sobre a alocação de recursos públicos, passando a incorpo- 
rar uma dimensão deliberativa que abrange abrangendo a construção do consenso, considerando peculiaridades e diferenças sociais.

Contudo, como foi analisado, os Orçamentos Participativos não conseguem resolver todos os problemas da população em regiões de baixa renda com elevada população. Portanto, na adaptação de tal instituto a outros municípios, deve ser observada adequada redistribuição dos gastos públicos com a adoção de programas específicos de acordo com as necessidades regionais no combate à pobreza.

Portanto, conforme explanado, conclui-se que é necessário que o Poder Público reflita sobre a necessidade do resgate da democracia direta participativa, seguindo o modelo porto-alegrense, porém considerando as especificidades locais na adequada redistribuição dos recursos, tornando o povo colaborador e corresponsável na destinação das verbas públicas, inibindo os administradores públicos de terem ampla liberdade com a coisa pública e se esquecerem de beneficiar a população.

\section{The participatory budgets as an instrument of popular participatory in effective public policy}

\section{Abstract}

The value of direct democracy is the object of political debate worldwide. The repulsion of the population policy and the current forms of representative democracy brings the debate on new forms of participation in particular with regard to the allocation of public funds. By analyzing participatory budgeting, it emphasizes the need to enhance participatory direct democracy, in order to give legitimacy to the decisions coming from the public and meet the community's problems.

Keywords: Direct Democracy, Repulsion. Participatory Budgets. Popular participation, democracy. 


\section{Referências}

ANDROLI, Antônio Inácio. O orçamento participativo de Porto Alegre: um exemplo para a Alemanha? Revista Espaço Acadêmico, Porto Alegre, ano 4, n. 43, dez. 2004.

ASSOCIAZIONE RETE DEL NUOVO MUNICIPIO. Disponível em: <http:// www.nuovomunicipio.org/>. Acesso em: 11 jun. 2010.

AVRITER, Leonardo. O orçamento participativo e a teoria democrática: um balanço crítico. Rede Brasileira de Orçamento Participativo, 2010. Disponível em: <http:// www.pbh.gov.br/redebrasileiraop/html/biblioteca/LeonardoAvritzer_port.pdf $>$. Acesso em: 11 jun. 2010.

AVRITER, Leonardo. Sociedade civil, esfera pública e poder local: uma análise do orçamento participativo em Belo Horizonte e Porto Alegre. Relatório final do projeto civil society and democratic governance, $2000 \mathrm{~b}$.

AZEVEDO, Sérgio de. Os desafios para o exercício da cidadania política nas sociedades modernas. In: SEMINÁRIO CIDADE, DEMOCRACIA E JUSTIÇA SOCIAL, 2003, Rio de Janeiro. Anais... Rio de janeiro, 2003.

BARCELLOS, Ana Paula de. Constitucionalização das políticas públicas em matéria de direitos fundamentais: o controle político-social e o controle jurídico no espaço democrático. In: SARLET, Ingo Wolfgang; TIMM, Luciano Benetti (Org.). Direitos fundamentais, orçamento e "reserva do possivel". Porto Alegre: Livraria do Advogado, 2008. p.111-147.

CANOTILHO, José Joaquim Gomes. Direito constitucional e teoria da Constituição. Coimbra: Almedina, 2001.

CRUZ, Álvaro Ricardo de Souza. Habermas e o direito brasileiro. 2.ed. Rio de Janeiro: Lúmen Júris, 2008.

FEDERACIÓN DOMINICANA DE MUNICIPIOS. Disponível em: <http://www. fedomu.org.do/index.html>. Acesso em: 18 mar. 2011.

FEDOZZI, L. J. Do patrimonialismo à cidadania participação popular na gestão municipal: o caso do orçamento participativo de Porto Alegre. 1996. $313 \mathrm{f}$. Dissertação (Mestrado em Sociologia)-Curso de Pós-Graduação em Sociologia, Universidade Federal do Rio Grande do Sul, 1996. 
FIGUEIREDO, Mariana Filchtiner. Reserva do possível, mínimo existencial e direito à saúde: algumas aproximações. In: SARLET, Ingo Wolfgang; TIMM, Luciano Benetti (Org). Direitos fundamentais, orçamento e "reserva do possível". Porto Alegre: Livraria do Advogado, 2008. p. 11-53.

HABERMAS, Jürgen. Direito e democracia entre a facticidade e a validade. 2. ed. Rio de Janeiro: Tempo Brasileiro, 2003. v. 1.

MAGALHÃES, José Luiz Quadros de. Direito constitucional. Belo Horizonte: Mandamentos, 2006. v. 3.

MARQUETTI, Ademir. Participação e redistribuição: o orçamento participativo em Porto Alegre. Projeto Democracia Participativa. Disponível em: $<$ http://www. democraciaparticipativa.org/files/AdalmirMarquettiParticipa\%E7\%E3oeRedistrib ui\%E7\%E3ooOr\%E7amentoParticipativoemPorto\%20Alegre.pdf>. Acesso em: 11 jun. 2010.

MELO, Danielle; AMARAL, Gustavo. Há direitos acima dos orçamentos? In: SARLET, Ingo Wolfgang; TIMM, Luciano Benetti (Org.). Direitos fundamentais, orçamento e "reserva do possível". Porto Alegre: Livraria do Advogado, 2008. p. 87-109.

MÜLLER, Friedrich. Quem é o povo? 4. ed. São Paulo: RT, 2008.

OHLWEILER, Leonel Pires. Políticas públicas e controle jurisdicional: uma análise hermenêutica à luz do Estado democrático de direito. In: SARLET, Ingo Wolfgang; TIMM, Luciano Benetti (Org). Direitos fundamentais, orçamento e "reserva do possivel". Porto Alegre: Livraria do Advogado, 2008. p. 323-345.

OLIVEIRA, Marcelo Andrade Cattoni de. Direito, política e filosofia: contribuições para uma teoria discursiva da constituição democrática no marco do patriotismo constitucional. Rio de Janeiro: Lúmen Júris, 2007.

ORÇAMENTO participativo. Disponível em: <http://www.op-portugal.org/index. php>. Acesso em: 11 jun. 2010.

ORÇAMENTO participativo. Prefeitura Municipal de Recife. Disponível em: $<$ http://www.recife.pe.gov.br/op/como.php>. Acesso em: 10 dez. 2010.

ORÇAMENTO participativo. Rede Brasileira de Orçamentos Participativos. Disponível em: <http://www.pbh.gov.br/redebrasileiraop/html/cid_part.htm>. Acesso em: 11 jun. 2010. 
PEREIRA, Rodolfo Viana. Direito constitucional democrático. Rio de Janeiro: Lúmen Júris, 2008.

PREFEITURA DE FORTALEZA. [Home Page]. Fortaleza, 2010. Disponível em: < http://www.fortaleza.ce.gov.br>. Acesso em: 18 mar 2011.

PRESSUPOSTOS participativos. Disponível em: $<$ http://www.presupuestos participativos.com>. Acesso em: 18 mar. 2011.

PRESSUPOSTOS participativos. Disponível em:<http://www.presupuestos participativo.cl/>. Acesso em: 18 mar. 2011.

SARLET, Ingo Wolfgang. A eficácia dos direitos fundamentais. 9. ed. Porto Alegre: Livraria do Advogado, 2008.

SARLET, Ingo Wolfgang. Algumas considerações em torno do conteúdo, eficácia e efetividade do direito à saúde na constituição de 1988. Revista Diálogo Jurídico, Salvador, n. 10, jan. 2002. Disponível em: <http://www.direitopublico.com.br $>$. Acesso em: 6 maio 2008.

SILVA, Marcelo Kunrath. Cidadania e exclusão: os movimentos sociais urbanos e a experiência de participação na gestão municipal de Porto Alegre. Porto Alegre: UFRGS, 2002.

SIMIONI, Rafael Lazzarotto. Direito e racionalidade comunicativa: a teoria discursiva do direito no pensamento de Jürgen Habermas. Curitiba: Juruá, 2007.

SIMIONI, Rafael Lazzarotto. Poder e autopoiese da política em Niklas Luhmann. Revista da Faculdade de Direito do Sul de Minas, Pouso Alegre, n. 27, p. 119-129, jul./dez. 2008.

SOARES, José Arlindo; SOLER, Salvador. Poder local e participação popular. Rio de Janeiro: Rio Fundo, 1992.

SOARES, Mário Lúcio Quintão. Teoria do estado. Belo Horizonte: Del Rey, 2001.

SOUZA, Celina. Construção e consolidação de instituições democráticas: papel do orçamento participativo. Revista São Paulo em Perspectiva: revista da Fundação Seade, São Paulo, v. 15, n. 4, out./dez. 2001.

TIMM, Luciano Benetti. Qual a maneira mais eficiente de prover direitos fundamentais: uma perspectiva de direito e economia? In: SARLET, Ingo Wolfgang; 
TIMM, Luciano Benetti (Org). Direitos fundamentais, orçamento e "reserva do possivel”. Porto Alegre: Livraria do Advogado, 2008. p. 55-68.

TORRES, Ricardo Lobo. O mínimo existencial, os direitos sociais e os desafios de natureza orçamentária. In: SARLET, Ingo Wolfgang; TIMM, Luciano Benetti (Org). Direitos fundamentais, orçamento e "reserva do possivel". Porto Alegre: Livraria do Advogado, 2008. p. 69-86. 